Tick Whai Lim MBBS MMED Anaesthesia, Easaw Thomas FFARACS FANZCA, Shu May Choo MBBS MMED Anaesthesia

\title{
Premedication with midazolam is more effective by the sublingual than oral route
}

Purpose: This study compared the sedative effects of sublingual tablet midazolam (Roche Dormicum $7.5 \mathrm{mg}$ ) with the oral route as premedication.

Methods: One hundred ASA physical status I and II gynaecological patients were randomly selected to receive a $7.5 \mathrm{mg}$ tablet of midazolam either sublingually or orally as premedication about one hour before elective surgery. There were 50 patients in each group. The degree of sedation was assessed according to the Ramsay scale initially and then at 20,30,45 and $60 \mathrm{~min}$ intervals by a second observer blinded to the route of administration. The time for complete drug dissolution was studied in the sublingual group by the inspection of tablet residue under the tongue every five minutes for $20 \mathrm{~min}$, then the patients were interviewed regarding their acceptance of the taste.

Results: The sedation scores in the sublingual group were higher than in the oral group at 30 and $60 \mathrm{~min}$ after drug administration. $(P=0.0054$ and $P=0.008)$ Seventy-two percent of the sublingual group had complete drug dissolution within $10 \mathrm{~min}$ and $64 \%$ of the patients in the sublingual group found the tablet acceptable with regard to its taste.

Conclusion: Midazolam $7.5 \mathrm{mg}$ sublingual is a more effective pre-anaesthetic sedative than by the oral route.

Objectif : Comparer les effets sédatifs du midazolam administré par la voie sublinguale (Dormicum Roche $7.5 \mathrm{mg}$ ) avec la voie orale.

Méthodes : En gynécologie. 100 patientes ASA I et II ont été choisies aléatoirement pour recevoir en prémédication du midazolam en comprimé oral ou sublingual de $7.5 \mathrm{mg}$ environ une heure avant une chirurgie élective. Chaque groupe comptait 50 patientes. La sédation était évaluée d'abord sur l'échelle de Ramsay et l'évaluation était répétée à des intervalles de 20,30, 45 et $60 \mathrm{~min}$ par un observateur neutre. L'intervalle jusqu'à la dissolution complète du comprimé sublingual était estimé par linspection du résidu oral toutes les cinq minutes pour 20 min. Par la suite, on demandait l'opinion des patientes sur son goût.

Résultats : Les scores de sédation du groupe sublingual étaient plus élevés dans le groupe oral 30 et $60 \mathrm{~min}$ après l'administration ( $P=0,0054$ et $P=0,008$ ). Soixante-douze pour cent des patientes du groupe sublingual ont trouvé le goût du comprimé sublingual acceptable.

Conclusion : En sédation préanesthésique. l'administration sublinguale de midazolam $7.5 \mathrm{mg}$ est plus efficace que l'administration orale.

From the Department of Anaesthesia, Kandang Kerbau Maternity Hospital, 1, Hampshire Road, Singapore 219428.

Address correspondence to: Dr. Tiek Whai Lim, Department of Anaesthesia and Surgical Intensive Care, New Changi Hospital, 2 , Simei Street 3, Singapore 529889. Phone: (65) 788-8833; E-mail: whai@pacific.net.sg

The study was supported by Roche (Singapore).

Acceted for publication April 13, 1997. 
$\mathrm{T}$

HE sublingual administration of the parenteral form of midazolam is an effective preanaesthetic agent in children. ${ }^{1}$ Sublingual administration of benzodiazepines such as lorazepam, brotizolam, triazolam, alprazolam and flunitrazepam have also been assessed for premedication. ${ }^{2-7}$ However, no study has evaluated the efficacy of sublingual tablet midazolam clinically. One advantage of the sublingual over the oral route is avoidance of first pass effect and an increase in bioavailablity of the drug and thus more predictable pharmacological effects.

The aim of this study was to compare the sedative effects of tablet $7.5 \mathrm{mg}$ midazolam (Roche Dormicum) administered for premedication by the oral or sublingual route. Also, the time taken for the sublingual tablets to dissolve completely and patient acceptance of the tablets with regard to taste were noted.

\section{Methods}

This study was approved by the Kandang Kerbau Maternity Hospital research ethical committee. With verbal consent, 100 female ASA physical status 1 or 2 gyneacological patients were randomly selected to receive premedication $7.5 \mathrm{mg}$ midazolam po or $s l$ prior to elective surgery. Excluded from the study were patients with a psychiatric history or those consuming psychotropic agents or tranquillisers. All patients were fasted overnight with no night sedation.

A baseline sedation score according to Ramsay ${ }^{8}$ (Table I) was noted by a second investigator blinded to the route of drug administration prior to serving the tablet. In the sl group, the tablet was placed under the tongue and patients were instructed not to swallow the tablets. The tablet was inspected every five minutes for 20 min until it had dissolved. In the po group, the tablet was taken with sips of water $(<20 \mathrm{ml})$. All patients were recumbent in bed when the study was started.

The sedation score was then recorded at $20,30,45$ and 60 min after drug administration in both groups by the second investigator. At the end of the study, the patients in the $s l$ group were asked whether the tablet was acceptable with regard to taste.

The demographic data were noted at the time of admission and intergroup differences were compared using Student's $t$ test. Sedation scores were compared globally between groups using the two way repeated measure ANOVA after log transformation of data, followed by Mann-Whitney U - Wilcoxon Rank Sum W Test for individual comparisons at adjusted $\alpha$ level. $P<0.01$ is taken as significant. Proportions were compared using chi-square tests accordingly.

\section{Results}

\section{Demographic data}

There were 50 patients in each group and there was no difference between them with respect to age, weight or height (Table II).

\section{Sedation scores between groups}

The overall sedation scores between the groups were different, $P=0.008$ (Figure 1 ). Both groups had comparable baseline sedation scores of level 1 or 2 . $(P=0.3171)$ Numerically higher sedation scores were recorded 20 and 45 min after drug administration for both groups, but the differences were not statistically significant $(P=0.269,0.0188$ respectively). At the 30 and $60 \mathrm{~min}$ intervals, the sedation scores in the $s l$ group were higher than in the po group $(P=0.0054$, $P=0.008$ respectively) (Table III).

The proportion of patients in the po group with scores of 24 increased from $23 / 50$ at $30 \mathrm{~min}$ to $29 / 50$ at $45 \mathrm{~min}$, whereas in the $s l$ group it was $38 / 50$ at both intervals. This may imply a slower onset of sedation in the po group. $(P=0.0045)$

At the 45 and $60 \mathrm{~min}$ intervals, the proportion of patients with scores of $\geq 5$ were $18 / 50,16 / 50$ in the po group and $27 / 50,28 / 50$ in the $s l$ group. This may imply a partial recovery in the po group. $(P=0.0043)$

TABLE I Ramsay Sedation Score

\begin{tabular}{|c|c|}
\hline Levels 1-3: & Levels 4-6: \\
\hline Patients awake & $\begin{array}{l}\text { Patients asleep, responses to light } \\
\text { glabellar tap or loud auditory } \\
\text { stimulus }\end{array}$ \\
\hline Level 1 & Level 4 \\
\hline $\begin{array}{l}\text { Anxious and agitated, or } \\
\text { restless, or both }\end{array}$ & Brisk response \\
\hline Level 2 & Level 5 \\
\hline $\begin{array}{l}\text { Co-operative, orientated and } \\
\text { tranquil }\end{array}$ & Sluggish response \\
\hline Level 3 & Level 6 \\
\hline Responds to commands only & No response \\
\hline
\end{tabular}

TARLE II Demographic data. Results expressed as mean $\pm \mathrm{SD}$

\begin{tabular}{lcccc}
\hline Group & Number $(n)$ & Weight (kg) & Height (cm) & Age (yr) \\
\hline Oral & 50 & $58.9 \pm 12.2$ & $157 \pm 5.5$ & $37 \pm 13.2$ \\
Sublingual & 50 & $58.0 \pm 11.0$ & $155 \pm 6.1$ & $39 \pm 11.7$ \\
Paired t test & & & & \\
2-tail significance & & $P=0.701$ & $P=0.144$ & $P=0.489$ \\
\hline
\end{tabular}


TABLE III Summary of patients' sedation scores at all time intervals and routes of drug administration

\begin{tabular}{|c|c|c|c|c|c|c|c|c|c|c|}
\hline \multirow{2}{*}{$\begin{array}{l}\text { Ramsay } \\
\text { Sedation Score }\end{array}$} & \multicolumn{2}{|c|}{ Start } & \multicolumn{2}{|c|}{$20 \mathrm{~min}$} & \multicolumn{2}{|c|}{$30 \mathrm{~min}$} & \multicolumn{2}{|c|}{$45 \mathrm{~min}$} & \multicolumn{2}{|c|}{$60 \mathrm{~min}$} \\
\hline & $p o^{*}$ & $s l$ & po & $s l$ & po & $s l$ & po & $s l$ & po & $s l$ \\
\hline 1 & 13 & 17 & 3 & 1 & 1 & 1 & 1 & 0 & 1 & 0 \\
\hline 2 & 36 & 33 & 24 & 20 & 14 & 5 & 11 & 2 & 13 & 1 \\
\hline 3 & 1 & 0 & 11 & 16 & 12 & 6 & 9 & 10 & 9 & 11 \\
\hline 4 & 0 & 0 & 6 & 5 & 10 & 16 & 11 & 11 & 11 & 10 \\
\hline 5 & 0 & 0 & 2 & 3 & 5 & 7 & 5 & 7 & 7 & 6 \\
\hline 6 & 0 & 0 & 4 & 5 & 8 & 15 & 13 & 20 & 9 & 22 \\
\hline Median & 2 & 2 & 2 & 3 & 3 & 4 & 4 & 5 & 4 & 5 \\
\hline $25 \%$ tile & 1.25 & 1 & 2 & 2 & 2 & 4 & 3 & 4 & 2 & 4 \\
\hline $75 \%$ tile & 2 & 2 & 3 & 3.75 & 4.75 & 6 & 5.75 & 6 & 5 & 6 \\
\hline 2 -tailed $P$ & \multicolumn{2}{|c|}{0.317} & \multicolumn{2}{|c|}{0.269} & \multicolumn{2}{|c|}{0.005} & \multicolumn{2}{|c|}{0.188} & \multicolumn{2}{|c|}{0.0008} \\
\hline
\end{tabular}

"po $=$ oral, $s l=$ sublingual

\section{Drug dissolution}

In the sublingual group, $44 \%$ had complete drug dissolution by five minutes. Another $28 \%$ took $10 \mathrm{~min}$, whereas $20 \%$ took $15 \mathrm{~min}$ and the last $8 \%$ took 20 min. The longer times for drug dissolution were frequently attributed to dry mouths (Figure 2 ).

\section{Acceptability of the sublingual tablet}

In the $s l$ group $32 / 50$ found the tablet acceptable with regard to taste.

\section{Discussion}

Midazolam, first synthesized in 1976, has become widely used for conscious sedation, premedication, brief diagnostic procedures and for inducing general anaesthesia. In our study, we found that $s l$ midazolam $7.5 \mathrm{mg}$ (Roche Dormicum) to be more effective as a preanaesthetic sedative than the po route.

A plasma level study of $s l$ tablet midazolam was first described by Fujii et al. in 1988.9 Three healthy volunteers were studied in a crossover study to compare plasma concentrations of midazolam after $p o$ and $s l$ administration. In the latter, the plasma concentration of midazolam increased rapidly and remained at higher levels for two hours and then slowly decreased while those following po administration increased rapidly but subsequently decreased rapidly. Reves et al. reported that only $40-50 \%$ of an orogastrically administrated dose of midazolam reaches the systemic circulation intact because of the extensive first-pass hepatic metabolism of the drug. ${ }^{10}$

The results of our study supported these findings clinically. The higher sedation scores observed in the $s l$ group at 30 and $60 \mathrm{~min}$ intervals would correspond to a higher plasma level of midazolam after drug administration. At the $45 \mathrm{~min}$ interval, the differences in sedation scores were not statistically significant. It can

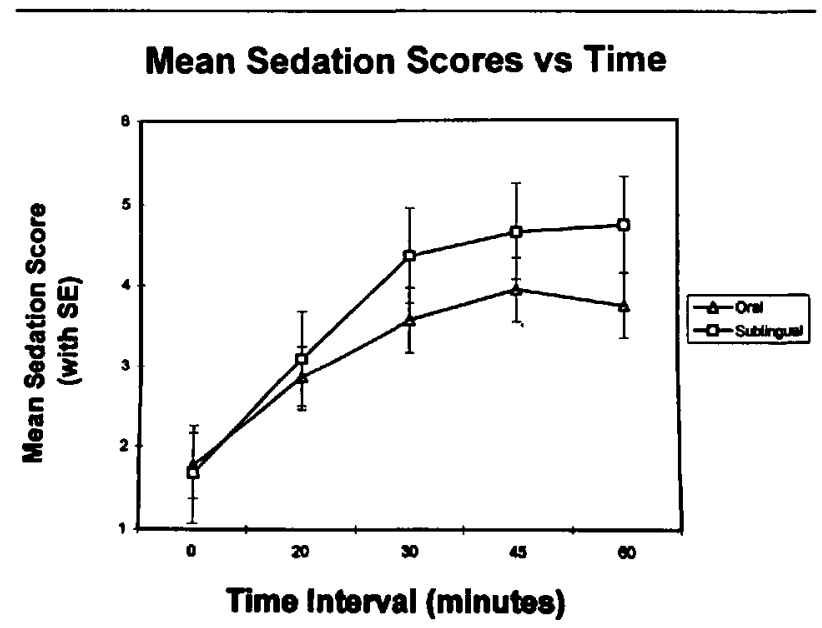

FIGURE 1 Mean Sedation Scores of patients versus time intervals.

\section{Sublingual Tablet Dissolve Time}

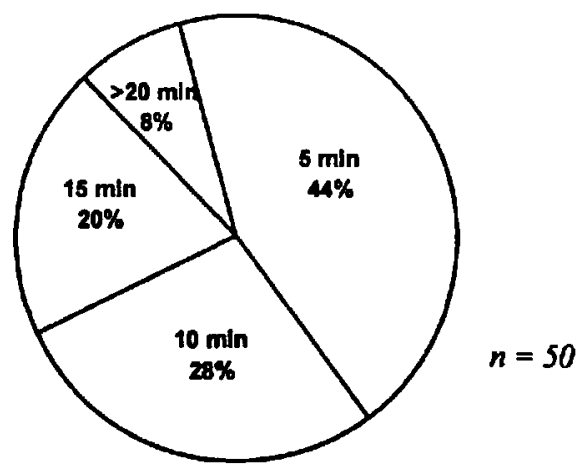

FIGURE 2 Time taken for tablet to dissolve in the sublingual group. 
be postulated that, in the oral group, there was a slower onset of higher sedation scores as well as an earlier recovery compared with the $s l$ group.

Premedication of an adult surgical patient with po midazolam is common practice in our institution. Although convenient, its effect may be unpredictable, resulting in lack of anxiolysis or sedation in some patients. ${ }^{11}$ The anxiolytic action of midazolam is present at plasma concentrations below those at which a sedative or hypnotic effect is detected. ${ }^{12}$ In addition, amnesia is a consistent and dose-related finding with benzodiazepines. ${ }^{13-15}$ Amnesia produced by a sedative agent can be a valuable clinical feature, as patients equate it with unconsciousnes. ${ }^{16}$ With $s / 7.5 \mathrm{mg}$ midazolam, effective sedation and other therapeutic goals can thus be more reliably achieved than by the po route.

This method of administering premedication also avoids the ingestion of additional fluids in preoperative patients. The other practical implication is the timing of serving the premedication. The early onset and longer duration of action in the sublingual route implies that premedication can be served anytime between 20 and $60 \mathrm{~min}$ before surgery and still result in satisfactory anxiolysis and sedation throughout. This is in contrast to the oral route whereby a variable onset and duration of action frequently result in unsatisfactory preoperative sedation in relation to timing of the surgery. However, whether this dose of sublingual midazolam alters the discharge fitness of our day surgery patients is still a subject for investigation.

The main disadvantage of this method is related to the bitter taste of the tablet. Although the tablet dissolved quite quickly, the bitter taste lingered and about a third of the patients found it to be unpleasant. Many methods to disguise the bitter taste of the parenteral preparation have been described to coax the paediatric patient, each claiming variable success. ${ }^{1,17-20}$ In the adult, a less elaborate way is required in making the tablet palatable. For example, one may consider adding mint flavouring to coat the tablet.

We conclude that for premedication in adults, tablet midazolam is a more effective sedative when given by the $s l$ than the po route.

\section{References}

1 Karl HW, Rosenberger $J L$, Larach $M G$, Rufflè JM.

Transmucosal adminstration of midazolam for premedication of pediatric patients. Anesthesiology 1993; 78 : 885-91.

2 Greenblatt DJ, Divoll M, Harmatz JS, Shader RI. Pharmacokinetic comparison of sublingual lorazepam with intravenous, intramuscular and oral lorazepam. J Pharm Sci 1982; 71 : 248-52.
3 Garzone $P D$, Kroboth $P D$. Pharmacokinetics of the newer benzodiazepines. Clin Pharmacokinet 1989; 16: 337-64.

4 Laur M, Espersen K, Ejlersen E, Krintel JJ. Sublingual premedication with brotizolam. Acta Anaesthesiol Scand $1992 ; 36: 764-6$.

5 Scavone JM, Greenblatt DJ, Friedman H, Shader RI. Enhanced bioavailability of trizolam following sublingual versus oral administration. Clin Pharmacol 1986; 26: 208-10.

6 Kontinen VK, Munuksela F- L, Sarvela J. Premedication with sublingual triazolam compared with oral diazepam. Can J Anaesth 1993; 40: 829-34.

7 Hüttel MS, Bang U. Sublingual flunitrazepam for premedication. Acta Anaesthesiol Scand 1985; 29: 209-11.

8 Ramsay MAE, Sapege TM, Simpson BRJ, Goodwin R. Controlled sedation with alphaxalone-alphadolone. BMJ 1974; 2: 656-9.

9 Fujii J,Inotsume $N$, Nakano $M$. Relative bioavailablity of midazolam following sublingual versus oral adminstration in healthy volunteers. Journal of PharmacobioDynamics 1988; 11: 206-9.

10 Reves JG, Fragen RJ, Vinik HR, Greenblatt DJ. Midazolam: pharmacology and uses. Anesthesiology $1985 ; 62$ : 310-24.

11 Raybould D, Bradshaw EG. Premedication for day case surgery. A study of oral midazolam. Anaesthesia 1987; 42: 591-5.

12 Amrein $R$, Eckert $M$, Haefeli $H$, Leishman $B$. Pharmacokinetic and clinical considerations in the choice of a hypnotic. Br J Clin Pharmacol 1983; 16: 5S-10.

13 White PF. Pharmacologic and clinical aspects of preoperative medication. Anesth Analg 1986; 65: 963-74.

14 Loeffler PM. Oral benzodiazepines and conscious sedation: a review. J Oral Maxillofac Surg 1992; 50: 989-97.

15 Stallworth JM, Martino-Saltzmann D. Comparison of benzodiazepine premedications triazolam and diazepam: amnesia, anxiolysis and sedation. Anesth Analg 1987; 66: S165.

16 Barclay JK, Hunter KMD, Mcmillan W. Midazolam and diazepam compared as sedatives for outpatient surgery under local analgesia. Oral Surg Oral Med Oral Pathol 1985; 59: 349-55.

17 Kupietzky A, Houpt MI. Midazolam: a review of its use for conscious sedation of children. Pediatr Dent 1993; 15: $237-41$.

18 Peterson MD. Making oral midazolam palatable for children (Letter). Anesthesiology 1990; 73: 1053.

19 Feld $L H$, Negus JB, White PF. Oral midazolam preanesthetic medication in pediatric outpatients. Anesthesiology 1990; 73: 831-4.

20 Anderson BJ, Exarchos $H$, Lee K, Brown TCK. Oral premedication in children: a comparison of chloral hydrate, diazepam, alprazolam, midazolam and placebo for day surgery. Anaesth Intensive Care 1990; 18: 185-93. 